
\title{
CIÊNCIANATURA
}

\section{Caracterização espacial da precipitação pluviométrica em bacias hidrográficas do Leste do Estado do Paraná}

\author{
Spatial characterization of rainfall in the eastern watershed of the State of Paraná
}

Paulo Miguel de Bodas Terassi ${ }^{1}$, Márcio Greyck Guimarães Correa ${ }^{2}$ e Emerson Galvani ${ }^{3}$

\author{
${ }^{1}$ Universidade de São Paulo, São Paulo, Brasil \\ pmbterassi@usp.br \\ ${ }^{2}$ Universidade de São Paulo, São Paulo, Brasil \\ mgreyckcorrea@gmail.com \\ ${ }^{3}$ Universidade de São Paulo, São Paulo, Brasil \\ egalvani@usp.br
}

\section{Resumo}

O presente trabalho objetiva caracterizar a distribuição espacial da precipitação pluviométrica em bacias hidrográficas da região Leste do Estado do Paraná, tendo como parâmetros principais a influência orográfica da Serra do Mar e marítima do Oceano Atlântico. Obtiveram-se os dados de pluviosidade de 54 postos pluviométricos e de 08 estações meteorológicas, que compreendem a série histórica de 1976 a 2015 .Para a elaboração das cartas de distribuição da precipitação pluviométrica foi utilizado o software ArcGis versão 10.3 e a interpolação dos dados foi feita através do método da Krigagem Ordinária.Os resultados demonstraram que a bacia hidrográfica Litorânea caracteriza-se pela maior pluviosidade média $(2.351 \mathrm{~mm})$, demonstrando o papel da maritimidade no acréscimo dos totais de pluviosidade. Com a barreira orográfica da Serra do Mar, a bacia hidrográfica do rio Ribeira obteve os menores valores da precipitação pluvial média anual $(1.488 \mathrm{~mm}) . A$ área em estudo caracteriza-se pela concentração de cerca de $70 \%$ dos totais anuais de pluviosidade no período de setembro a março.

Palavras-chave: Efeito orográfico. Maritimidade. Precipitação.

\section{Abstract}

This paper aims to characterize the rainfall spatial distribution in the watersheds of the eastern region of the Parana State, considering as the main parameters the orographic influence of the Serra do Mar and maritime of the Atlantic Ocean.Rainfall data were obtained from 54 pluviometric stations and from eight meteorological stations, which comprise historical series from 1976 to 2015.For the preparation of rainfall distribution charts, was used the ArcGis software version 10.3 and the data interpolation was done using the Ordinary Kriging method. The results showed that the Litorânea watershed is characterized by the highest average rainfall $(2,351 \mathrm{~mm})$, demonstrating the maritime role in the rainfall totals increases. With the orographic barrier of Serra do Mar, the Ribeira watershed obtained the lowest values of the average annual rainfall $(1,488 \mathrm{~mm})$. The study area is characterized by the concentration of about $70 \%$ of annual rainfall totals in the period from September to March.

Keywords: Orographic Effect. Maritimity .Rainfall. 


\section{Introdução}

Exceção dada aos climas tropicais semi-áridos, a precipitação pluviométrica corresponde ao atributo climático de maior importância em regiões de clima tropical (ÁLVARES et. al., 2013), uma vez que a energia térmica nos trópicos é superavitária devido às elevadas temperaturas e à baixa amplitude térmica. Pereira et. al. (2002) menciona que nos países tropicais, a precipitação pluvial corresponde a forma principal pela qual a água retorna da atmosfera para a superfície terrestre após os processos de evaporação e condensação, completando o ciclo hidrológico.Portanto, a abundância pluviométrica é uma das principais características do clima tropical e, entretanto, a distribuição dos totais da precipitação pluvial em escalas temporais e espaciais ocorrem em diferentes ritmos nas distintas localidades, o que se atribui aos fatores que geram as chuvas.

Um dos principais fatores na geração da precipitação pluviométrica é a maritimidade. Geralmente, a proximidade das terras continentais com os oceanos influencia na geração de maiores totais pluviométricos para as zonas litorâneas, mormente naquelas mais próximas às correntes marítimas quentes. Em regiões de clima tropical, as elevadas temperaturas e o elevado conteúdo de umidade advindos do oceano para o continente são responsáveis pela constante formação de chuvas convectivas, marcadas pela intensidade e pelos maiores históricos de precipitação pluviométrica do Globo Terrestre. Excepcionalmente, as regiões próximas as correntes mais frias são aquelas que estão associadas às menores taxas anuais de precipitação pluvial, o que se deve a redução significativa do potencial de formação das chuvas e coincidem com as regiões desérticas ou semi-áridas (PELL et. al., 2007).

Um dos atributos de maior relevância para o entendimento da distribuição espacial da precipitação pluviométrica, o efeito orográfico é comumente definido como a atribuição da morfologia do relevo na interação com a dinâmica atmosférica (PELLEGATTI; GALVANI, 2010). A chuva orográfica tem a sua gênese na ascensão da parcela de ar úmido sobre a rugosidade do relevo, na perda de temperatura sem troca com o meio, na formação de nebulosidade e, consequentemente, em maiores totais de precipitação na encosta denominada de barlavento. Inversamente, ao transpor a barreira orográfica, o fluxo de ar torna-se descendente e, com a perda do conteúdo higrométrico, a vertente situada no reverso deste processo caracteriza-se pelos menores totais pluviométricos e recebe a denominação de sotavento (LEOPOLD, 1949; MILANESI; GALVANI, 2011; FOGARINI et. al., 2014).

Este trabalho investiga a influência orográfica da Serra do Mar frente ao desempenho da maritimidade para a distribuição da precipitação pluviométrica em bacias hidrográficas da região Leste paranaense. Os estudos acerca do efeito orográfico na distribuição das chuvas em bacias hidrográficas são de alta relevância, pois a orografia é um importante fator atuante na dinâmica dos elementos constituintes do clima, de forma a intensificar ou reduzir os totais pluviométricos (ARAÚJO et. al., 2008; CANDIDO; NUNES, 2008; SELUCHI et. al., 2011; CHIERICE; LANDIM, 2014).

Destaca-se que as bacias hidrográficas foram selecionadas por corresponder a uma célula básica da análise ambiental e, devido a sua estrutura e dinâmica, possibilitar compreender as características dos recursos hídricos em função da organização geológico-geomorfológica e as condições climáticas, subsidiando o planejamento integrado e sistêmico (PORTO; PORTO, 2008; CARVALHO, 2014).

Com estas premissas, o presente trabalho objetiva caracterizar a distribuição espacial da precipitação pluviométrica em bacias hidrográficas da região Leste do Estado do Paraná, tendo como parâmetros principais a influência orográfica da Serra do Mar e marítima do Oceano Atlântico. 


\section{Localização e caracterização da área de estudo}

A área selecionada para o presente estudo corresponde às bacias hidrográficas do Alto Iguaçu, Ribeira e Litorânea, situadas no setor leste do estado do Paraná, entre os meridianos $48^{\circ} \mathrm{W}$ e $50^{\circ} \mathrm{W}$ e os paralelos $24^{\circ} \mathrm{S}$ e $26^{\circ} \mathrm{S}$, e apresentam, respectivamente, a abrangência de $10.261 \mathrm{~km}^{2}, 9.736 \mathrm{~km}^{2}$ e $5.630 \mathrm{~km}^{2}$ (ITCG, 2016), conforme mostra a Figura 1. As bacias hidrográficas em estudo estão inseridas em quatro unidades da divisão geomorfológica proposta por Maack (2012), originalmente publicada em 1968: a Zona Litorânea; a Serra do Mar; o Primeiro Planalto (Curitiba); e o Segundo Planalto (Ponta Grossa).

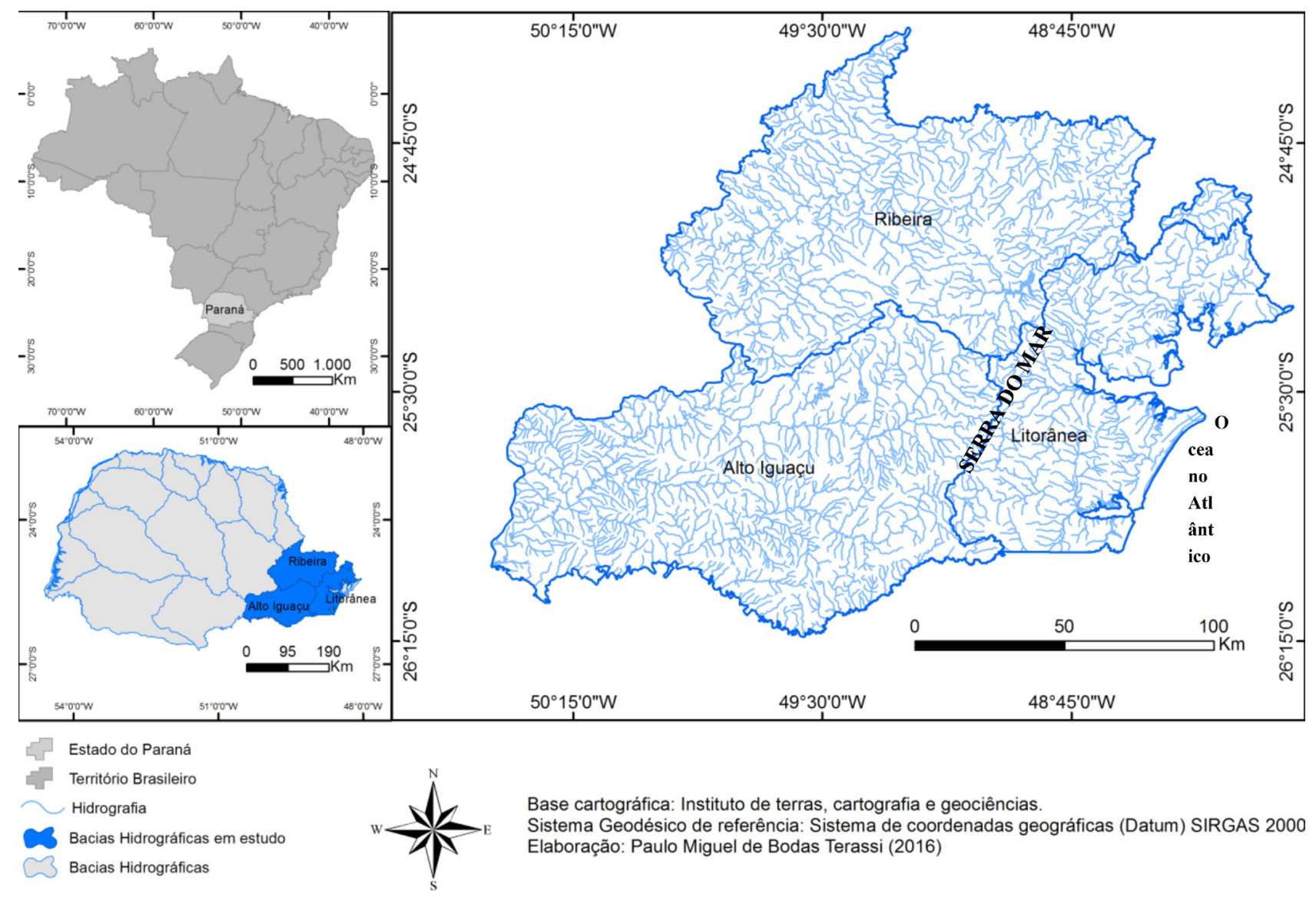

Figura 1 - Localização das bacias hidrográficas do Alto Iguaçu, Litorânea e Ribeira - Paraná.

A maior parte da área de estudo está situada no Escudo Paranaense, que se constitui no setor mais antigo e elevado, formado essencialmente por rochas cristalinas, ígneas e metamórficas, da Plataforma Sul-Americana, e pelas rochas sedimentares, que remontam ao Arqueano, de maior grau metamórfico e ao paleozóico inferior, com as rochas magmáticas ácidas, e ao paleozóico, com as bacias vulcano-sedimentares. O setor oeste da bacia hidrográfica do Alto Iguaçu situa-se parcialmente na Bacia Sedimentar do Paraná, com as rochas do paleozóico superior, dos grupos Guatá e Passa Dois. Principalmente a sudeste da bacia hidrográfica Litorânea, verifica-se a ocorrência dos sedimentos inconsolidados do Cenozóico (THOMAZ, 1984; MINEROPAR, 2001).

A tipologia climática de Köppen (1948) "Cfb" (subtropical úmido brando sem estação seca definida) é predominante para a bacia hidrográfica do Alto Iguaçu, conforme apontam Cavaglione et. al. (2000) e Álvares et. al. (2013). A bacia Litorânea é o setor de maiores temperaturas dentre as bacias hidrográficas selecionadas, com médias anuais próximas a $21^{\circ} \mathrm{C}$, com máximas superiores a $24^{\circ} \mathrm{C}$ em janeiro e fevereiro e, contudo, inferiores a $16^{\circ} \mathrm{C}$ em julho, 
sendo o tipo climático predominante nesta bacia hidrográfica é o "Cfa" (subtropical quente sem estação seca definida), conforme Cavaglione et. al. (2000), Vanhoni e Mendonça (2008) e Álvares et. al. (2013). Na bacia hidrográfica do rio Ribeira, as características térmicas indicaram temperaturas médias inferiores a $16^{\circ} \mathrm{C}$ para o mês mais frio (julho), condição inerente ao clima subtropical e, desta forma, com a predominância do clima "Cfa" para os setores de menores altitudes e de médias térmicas superiores a $22^{\circ} \mathrm{C}$ nos meses de verão e, especificamente nas maiores altitudes, a ocorrência da tipologia climática "Cfb" para as porções de maiores altitudes e médias térmicas inferiores a $22^{\circ} \mathrm{C}$ no mês mais quente. A transição entre os tipos climáticos de Köppen (1948) "Cfa" e "Cfb" foi obtida anteriormente por Cavaglione et. al. (2000) e Álvares et. al. (2013) e restringe-se apenas a descriminar a variação espacial da temperatura média dos meses de verão em conformidade a altimetria da bacia hidrográfica do rio Ribeira.

\section{Materiais e Métodos}

Obtiveram-se os dados de precipitação de 54 postos pluviométricos pertencentes à Agência Nacional de Águas (ANA), à Companhia Paranaense de Energia (COPEL) e ao Instituto das Águas do Paraná, e de 08 estações meteorológicas, ao Instituto Agronômico do Paraná (IAPAR), Instituto Nacional de Meteorologia (INMET) e ao Sistema Meteorológico do Paraná (SIMEPAR), que compreendem a série histórica de 1976 a 2015 (Figura 2).

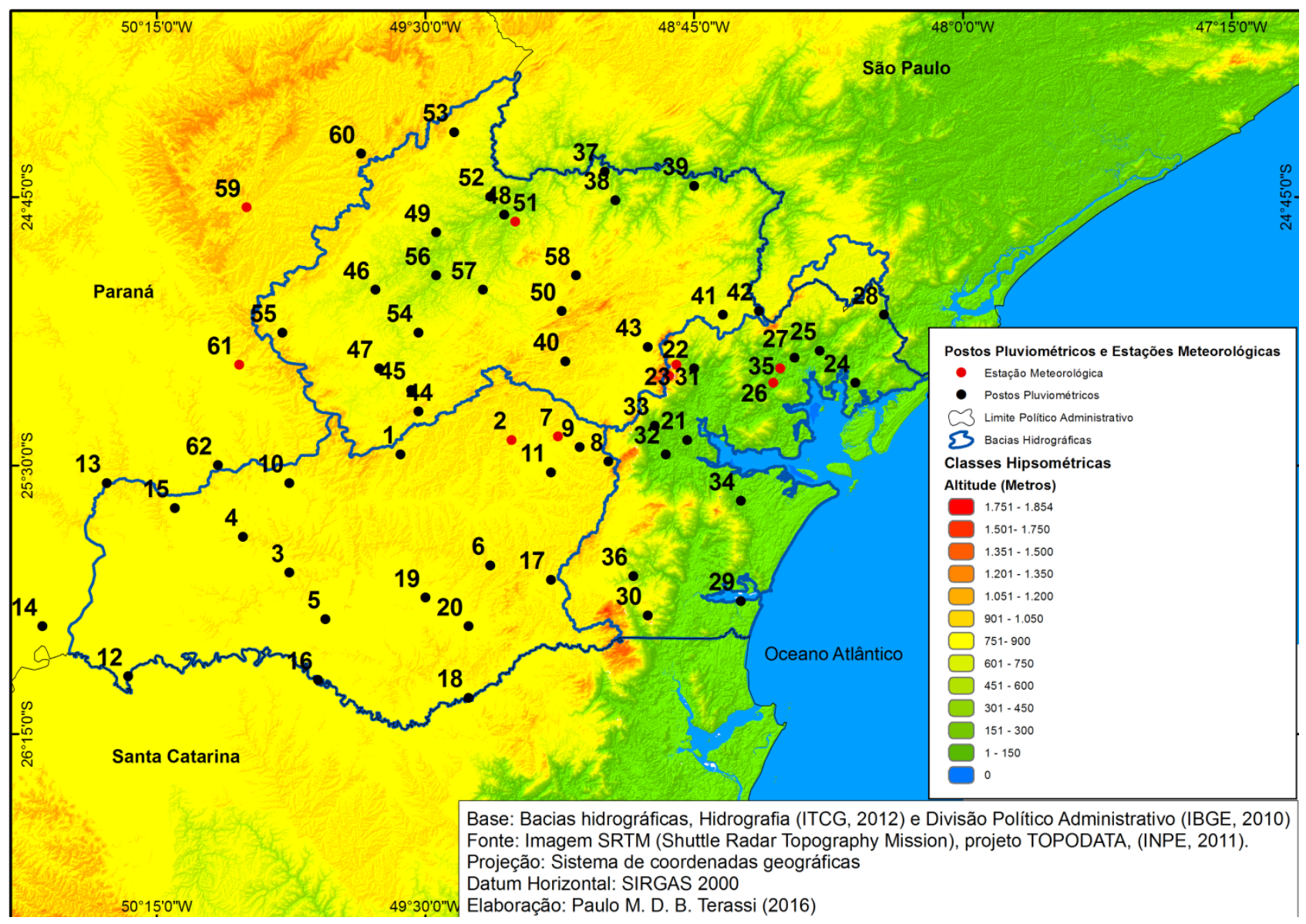

Figura 2 - Localização geográfica e hipsometria dos postos pluviométricos e estações meteorológicas dentro e no entorno das bacias hidrográficas do Alto Iguaçu, Ribeira e Litorânea - Paraná.

As estações meteorológicas e os postos pluviométricos inseridos no entorno das bacias hidrográficas foram selecionadas para preencher adequadamente a pluviometria do recorte espacial e a ausência de registros, conforme 
preconizado por Bertoni e Tucci (1997).Os dados faltantes dos postos pluviométricos e estações meteorológicas foram preenchidos seguindo o método de ponderação regional de Villela e Matos (1975). Esse método tem como base o registro pluviométrico de três postos localizados o mais próximo possível do posto em que se verifica a falta de dados, com características pluviométricas (distribuição mensal e sazonal) e altitudes semelhantes (LEIVAS et. al., 2006; OLIVEIRA et. al., 2010). Considerando x o posto que apresente a falha e por A, B e C os postos vizinhos, é possível determinar a precipitação (Px) desse posto x pela média ponderada do registro dos três postos vizinhos, onde os pesos são as razões entre as precipitações anuais normais, representados pela equação 1.

$\mathrm{Px}=\frac{\mathrm{P}^{\prime} \mathrm{x}}{3}\left(\frac{\mathrm{Pa}}{\mathrm{Pa}^{\prime}}+\frac{\mathrm{Pb}}{\mathrm{Pb}^{\prime}}+\frac{\mathrm{Pc}}{\mathrm{P}^{\prime}}\right) P x=\frac{\mathrm{P}^{\prime} \mathrm{x}}{3}\left(\frac{\mathrm{Pa}}{\mathrm{Pa}^{\prime}}+\frac{\mathrm{Pb}}{\mathrm{Pb}^{\prime}}+\frac{\mathrm{Pc}}{\mathrm{P}^{\prime} \mathrm{c}}\right)(1)$

Em que: $\mathrm{x}$ é o posto pluviométrico ou estação meteorológica com dados pluviométricos faltantes; Px é a precipitação do mês faltante; $P$ x́ é a precipitação média mensal da estação x; $\mathrm{Pa}, \mathrm{PaPb} \mathrm{Pb}, \mathrm{Pc}$ são as precipitações mensais reais dos postos pluviométricos selecionados para o preenchimento; e $P^{\prime} a, P ́ b, P^{\prime}$ são as precipitações médias mensais destes mesmos postos.

Para a melhor organização das informações optou-se por realizar a análise dos dados de precipitação para a escala anual e mensal utilizando-se de parâmetros estatísticos básicos em planilha eletrônica Microsoft Office Excel $2007^{1}$. Para verificar as relaçoos entre elementos (precipitação pluviométrica) e fatores (altimetria) climáticos utilizouse a correlação linear de Pearson (Equação 2), que segundo Yakamoto e Landim (2013) permite avaliar numa medida da intensidade de uma linearidade entre duas variáveis através de coeficientes cujos valores variam entre -1 e +1 . O valor zero, no caso, significa que não há relação linear; o valor +1 indica uma relação linear perfeita; e o valor -1 também indica uma relação linear perfeita inversa. Portanto, quanto mais próximo estiver de +1 ou -1 , mais forte é a associação linear entre as duas variáveis, diretamente ou inversamente proporcional.

$r=\frac{\sum\left(x_{i}-\dot{x}\right)\left(y_{i}-\dot{y}\right)}{\sqrt{\left(\sum\left(x_{i}-\dot{x}\right)^{2}\right)\left(\sum\left(y_{i}-\dot{y}\right)^{2}\right)}}$

Em que: $\mathrm{x}_{\mathrm{i}}$ e $\mathrm{y}_{\mathrm{i}}$ indicam as duas variáveis observadas em cada passo de tempo i; $\dot{x}$ e $\dot{y}$, a média aritmética de cada série temporal; $\sqrt{\left(\sum\left(x_{i}-\dot{x}\right)^{2}\right)\left(\sum\left(y_{i}-\dot{y}\right)^{2}\right)}$ corresponde ao desvio padrão de $\mathrm{x}$ e y.

Utilizou-se o coeficiente de determinação $\left(\mathrm{r}^{2}\right)$, que fornece uma informação auxiliar ao resultado da variância da regressão apresentada pela correlação linear, pois identifica a validade comparativa entre os componentes avaliados. $\mathrm{O}$ valor de $\mathrm{r}^{2}$ varia no intervalo de 0 a 1 , sendo que os valores mais próximos de 1 indicam que ocorre uma adequada relação na descrição do conjunto em análise (ANDRIOTTI, 2003).Os gráficos de representação dos resultados de dispersão, coeficiente de determinação, correlação linear de Pearson e perfis esquemáticos foram realizado a partir do software Microsoft Office Excel 2007.

Aplicou-se o teste de significância estatística t de Student (com n-2 graus de liberdade) com a finalidade de testar a significância das correlações entre as variáveis estudadas. $O$ teste de significância $t$ de Student fornece graus de confiabilidade em porcentagem e o nível de significância foi de 97,5\%.A seguir a fórmula do teste de significância (Equação 3).

$t_{n-2}=r \sqrt{\frac{n-2}{1-r^{2}}}(3)$

1 Microsoft Office Excel 2007 é um produto registrado Microsoft Corporation. 
Em que r é o coeficiente de correlação; $r^{2}$ é o coeficiente de determinação; e n é o número da amostra.

As representações gráficas da relação entre a altitude e a precipitação em perfis esquemáticos na escala anual e para os meses de maior (janeiro) e menor (agosto) precipitação média para averiguar a relação entre a orografia e maritimidade para a distribuição espacial pluviométrica. As estações meteorológicas e os postos pluviométricos foram ordenados seguindo as características do relevo das bacias hidrográficas, configurando-se das menores para as maiores altitudes para a bacia hidrográfica Litorânea e inversamente para as bacias hidrográficas do rio Ribeira e Alto Iguaçu.

Para a elaboração das cartas de distribuição da precipitação pluviométrica foi utilizado o software ARCGIS versão 10.3. Utilizando-se do arquivo com o contorno da área de estudo digitalizado, em formato shapefile com os valores de longitude e latitude, e outro arquivo shapefile com os valores calculados de cada estação meteorológica e postos pluviométricos, com suas respectivas coordenadas geográficas.

A interpolação dos dados foi feita através do método da Krigagem Ordinária, considerado o mais adequado para este tipo de interpolação, por permitir uma representação mais adequada da continuidade dos fenômenos geográficos como a precipitação pluviométrica, conforme apontado por Carvalho e Assad (2005), Góis et. al. (2015) e Mello e Oliveira (2016).

Landim (2004) esclarece que a krigagem compreende um processo para estimar os valores de variáveis distribuídas no espaço a partir de valores adjacentes considerados como interdependentes pelo semivariograma. O semivariograma infere sobre a medida do grau de dependência espacial entre amostras, expressando a variação espacial da variável regionalizada (MELLO; OLIVEIRA, 2016).

Como se utilizou um número significativo de postos pluviométricos e estações meteorológicas recorreu-se a elaboração de semivariogramas experimentais que permitiram verificar que a associação do modelo de variograma Nugget Effect ao Esférico foi a mais adequada para a krigagem, pois combinados demonstraram a menor quantidade de núcleos isolados de isoietas e os intervalos gerados para estas isolinhas foram as mais próximas em relação aos valores reais dos intervalos máximos e mínimos de precipitação pluviométrica.

\section{Resultados e Discussões}

A bacia hidrográfica Litorânea caracteriza-se pelos maiores totais anuais pluviométricos da área de estudo, com uma média $2.351 \mathrm{~mm}$, com isoietas superiores a $2.600 \mathrm{~mm}$ a nordeste e inferiores a $1.900 \mathrm{~mm}$ em seu setor oeste, nas proximidades com a Serra do Mar. Com os menores totais anuais pluviométricos, equivalentes a $1.488 \mathrm{~mm}$, a bacia hidrográfica do Ribeira apresenta totais anuais de chuva superiores a $1.800 \mathrm{~mm}$ no setor sudeste, nas proximidades da Serra do Mar e inferiores a $1.400 \mathrm{~mm}$ ao norte, nos setores de menores altitudes. Dada a sua condição homogênea das elevações do terreno, a bacia hidrográfica do Alto Iguaçu mostrou uma média anual de 1.571,9 mm, com a predominância de totais anuais pluviométricos entre 1.501 a $1.600 \mathrm{~mm}$ (Figura 3).

Estes resultados estão de acordo com os obtidos por Cavaglione et. al. (2000) para os setores do estado do Paraná que situam-se estas bacias hidrográficas. Estes autores observaram que a bacia hidrográfica Litorânea apresenta maiores totais pluviométricos superiores a $2.500 \mathrm{~mm}$ nos setores nordeste e central, enquanto que nas demais áreas predominam os intervalos de isoietas entre 2.000 a $2.500 \mathrm{~mm}$. Obtiveram a maior abrangência entre os intervalos de 1.400 a $1.600 \mathrm{~mm}$ nas bacias hidrográficas Ribeira e Alto Iguaçu e os menores valores de pluviosidade, entre 1.200 a $1.400 \mathrm{~mm}$, identificados nos setores de menores elevações no vale do Ribeira.

Os gráficos de dispersão permitiram identificar os padrões predominantes de precipitação pluviométrica para as bacias hidrográficas. Observa-se uma relativa homogeneidade da precipitação pluviométrica média anual dos postos 
pluviométricos e estações meteorológicas inseridas na bacia hidrográfica do Alto Iguaçu, entre $1.400 \mathrm{~mm}$ a $1.600 \mathrm{~mm}$, exceto um dos postos pluviométricos que apresenta precipitação média aproximada de $1.900 \mathrm{~mm}$, e os resultados de coeficiente de determinação e correlação linear de Pearson mostram pouca influência do relevo para a variação pluviométrica (Figura 4). Com os maiores totais pluviométricos da área de estudo, nota-se para a bacia hidrográfica Litorânea uma variação pluviométrica anual entre 2.000 a $2.800 \mathrm{~mm}$, com valores insignificativos do coeficiente de determinação e correlação linear com as altitudes dos postos de registros, o que se atribui principalmente ao predomínio das baixas altitudes da referida bacia hidrográfica (Figura 5). A bacia hidrográfica do Ribeira caracteriza-se pela maior heterogeneidade pluviométrica, com intervalo predominante entre 1.200 a 1.600 e, entretanto, dois postos de registros com precipitação anual superior a $1.750 \mathrm{~mm}$, com os maiores valores de coeficiente de determinação e correlação linear com o relevo, dada a maior variação das altitudes dos postos pluviométricos e estações meteorológicas nesta bacia hidrográfica (Figura 6).

Os resultados do teste de significância mostraram que o conjunto de dados apresentou não significância para as bacias hidrográficas do Alto Iguaçu e Litorânea, corroborando o menor desempenho da orografia na distribuição espacial da pluviosidade para estas áreas em estudo. Este mesmo teste demonstrou que o conjunto de dados apresenta uma significância superior a 97,5\% para a bacia hidrográfica do Ribeira, o que revela a maior relevância do fator orográfico para a distribuição espacial da precipitação pluviométrica deste setor em estudo.

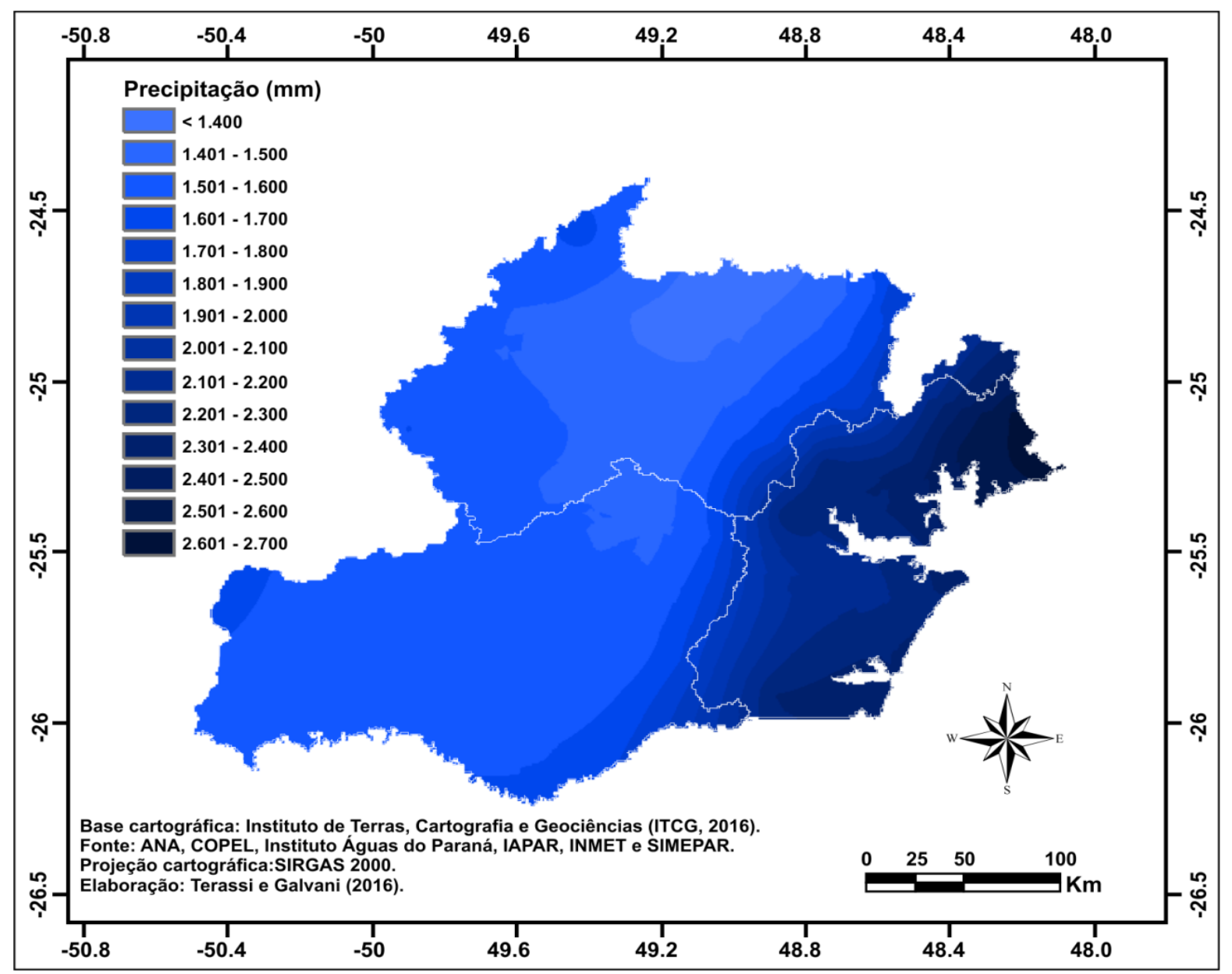

Figura 3 - Distribuição espacial da precipitação (mm) para as bacias hidrográficas do Alto Iguaçu, Ribeira e Litorânea (PR) para o período de 1976 a 2015. 


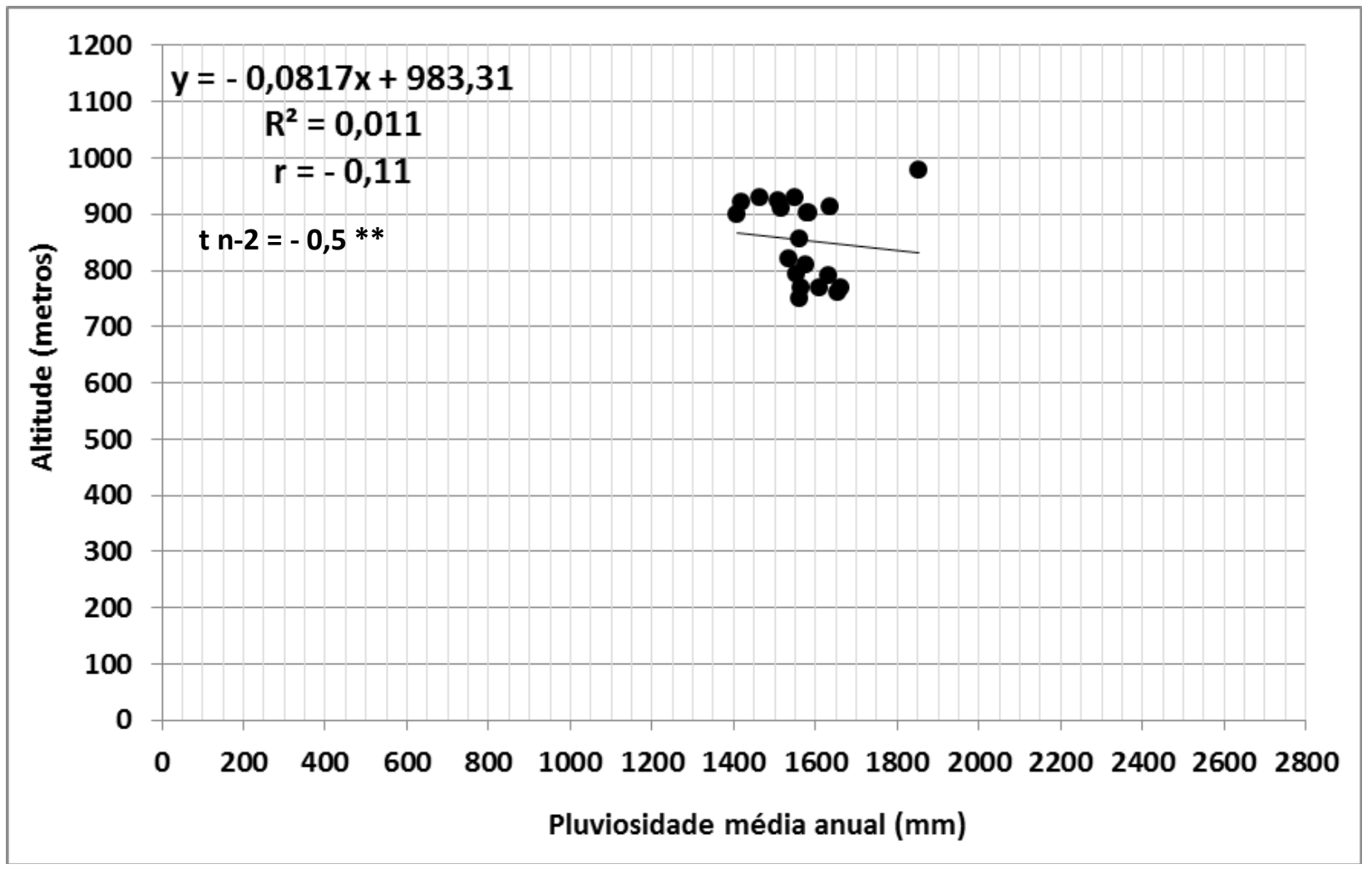

Figura 4- Dispersão gráfica, coeficiente de determinação, correlação linear de Pearson, não significativo ao nível de $97,5 \%$ pelo teste t de Student $(* *)$ entre a pluviosidade média anual $(\mathrm{mm})$ e a altitude (metros) dos postos pluviométricos e das estações meteorológicas inseridas na bacia hidrográfica do Alto Iguaçu - Paraná.

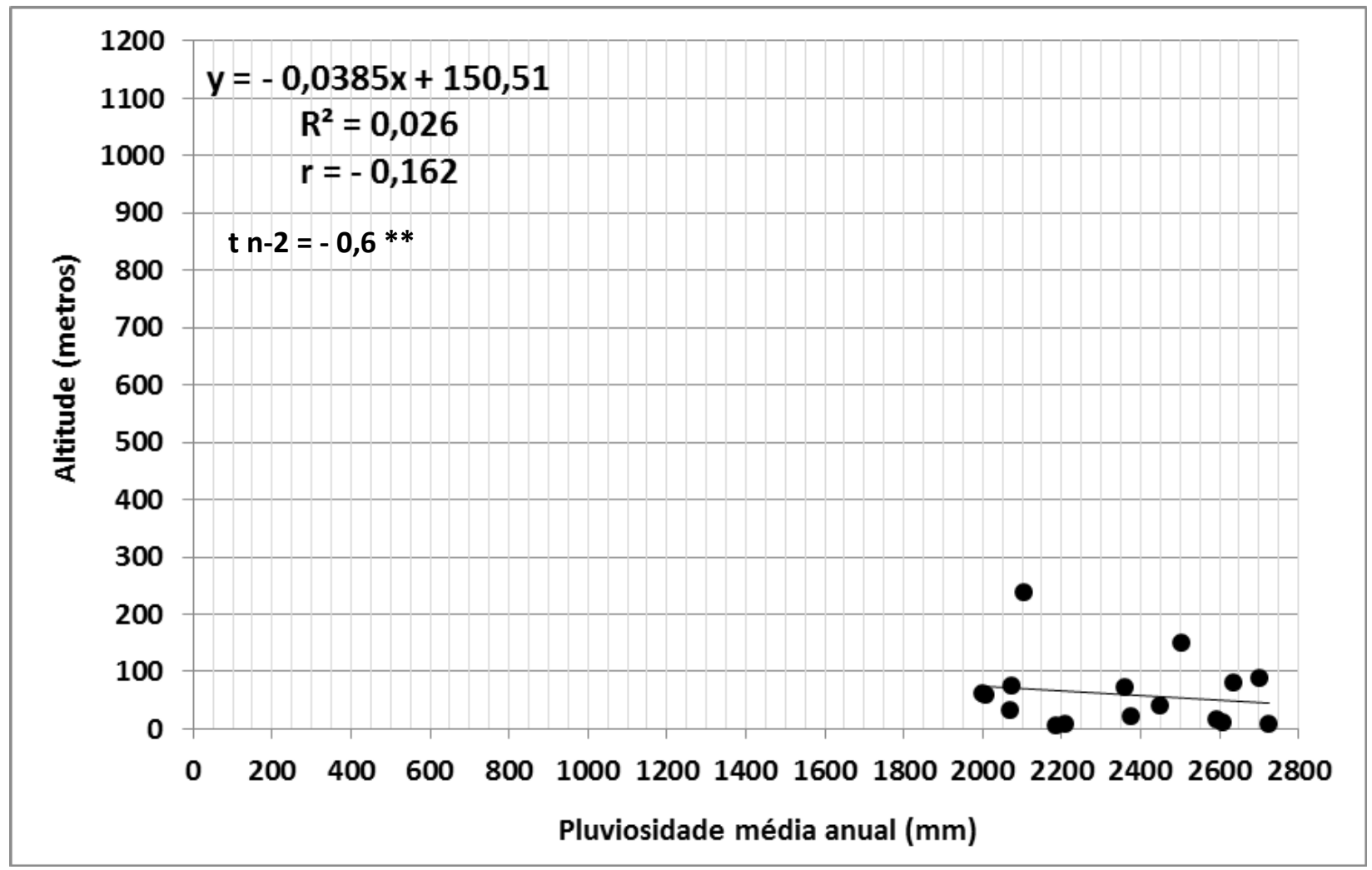

Figura 5 - Dispersão gráfica, coeficiente de determinação, correlação linear de Pearson, não significativo ao nível de $97,5 \%$ pelo teste t de Student $(* *)$ entre a pluviosidade média anual $(\mathrm{mm})$ e a altitude (metros) dos postos pluviométricos e das estações meteorológicas inseridas na bacia hidrográfica Litorânea - Paraná. 


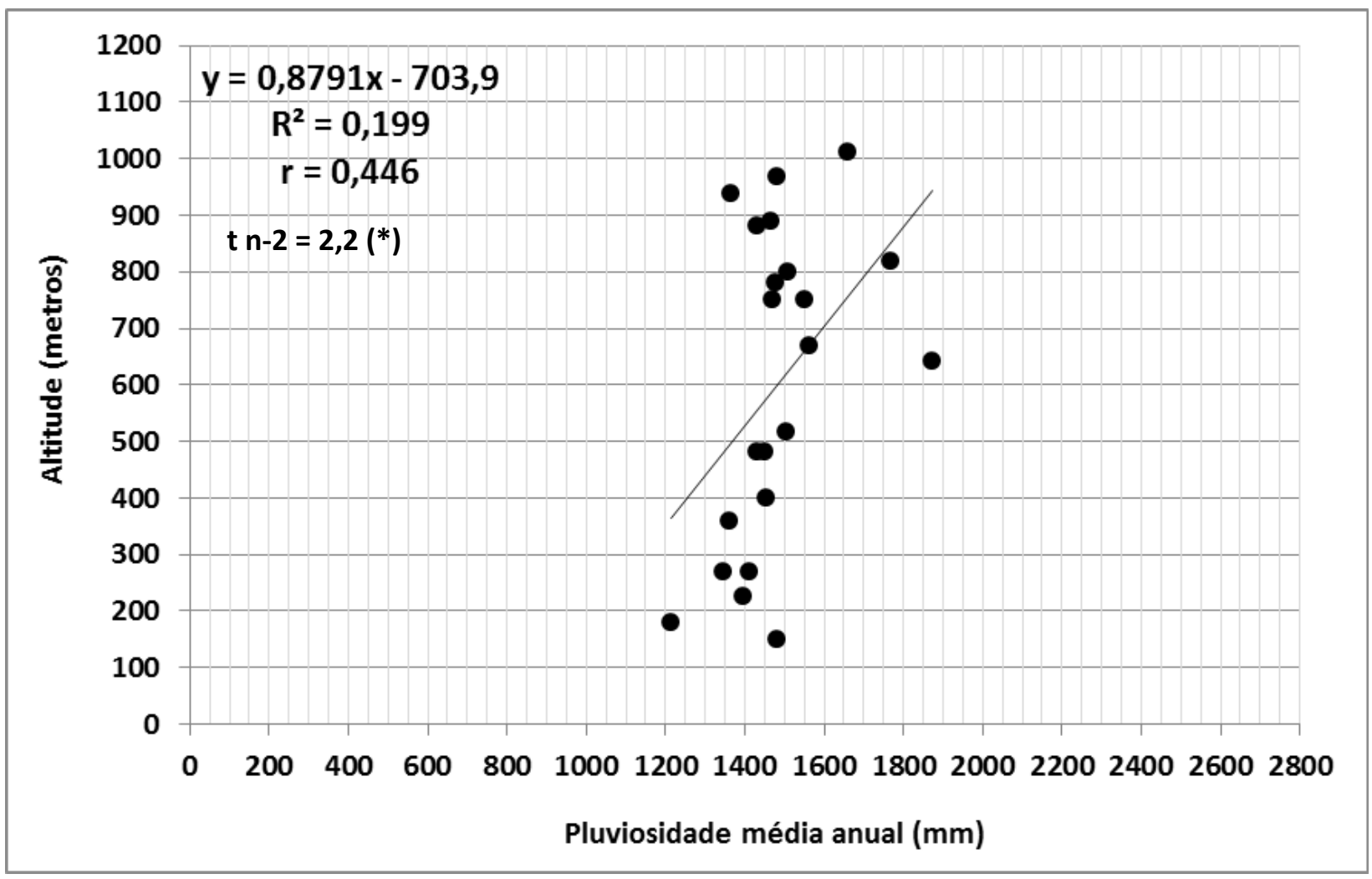

Figura 6 - Dispersão gráfica, coeficiente de determinação e correlação linear de Pearson, significativo ao nível de $97,5 \%$ pelo teste t de Student (*) entre a pluviosidade média anual $(\mathrm{mm})$ e a altitude (metros) dos postos pluviométricos e das estações meteorológicas inseridas na bacia hidrográfica do Ribeira - Paraná.

A relação entre a orografia, a maritimidade e a distribuição espacial das chuvas está demonstrada de forma simplificada pelo perfil esquemático com as altitudes e a precipitação média anual dos postos pluviométricos e estações meteorológicas. Na bacia hidrográfica Litorânea, os setores de menores altitudes apresentam maiores totais pluviométricos, próximo a $2.700 \mathrm{~mm}$, destacando o efeito da maritimidade para a geração de maiores totais de chuvas, enquanto que o setor oeste, caracterizado pelas maiores elevações do terreno, mostrou uma redução dos totais pluviométricos anuais $(2.000 \mathrm{~mm})$. Na bacia hidrográfica do Ribeira a orografia desempenha um papel inverso em relação à bacia Litorânea, tendo em vista que os setores mais elevados obtiveram maiores médias pluviométricas anuais, e os postos de registros com menores altitudes caracterizam-se por totais pluviométricos, demonstrando uma maior influência do relevo para a distribuição espacial pluviométrica. Generalizadamente, a bacia hidrográfica do Alto Iguaçu caracteriza-se por uma maior homogeneidade da distribuição espacial pluviométrica, dada a maior homogeneidade das altitudes dos pontos de registros para este setor (Figura 7).

Assim como na zona costeira do estado de São Paulo (SANT’ANNA NETO, 1994), a maritimidade aliada à atuação intensificada dos sistemas atmosféricos intertropicais e a predominância dos sistemas frontais na geração de chuvas, respondem pelos elevados totais pluviométricos na Planície Costeira paranaense, como observado por Maack (2012). Fritzsons et. al. (2011) descrevem que o Litoral do Paraná apresenta as maiores pluviometrias do território paranaense devido ao fator orográfico da Serra do Mar, brisa marítima e o contraste térmico entre a terra e as águas interiores. A localização geográfica em relação a Serra do Mar atribui à bacia hidrográfica do rio Ribeira uma condição atípica da distribuição pluviométrica para esta latitude, uma vez que para o setor Meridional do território paranaense predomina a homogeneidade do regime mensal das chuvas devido às características próprias à dinâmica atmosférica do clima subtropical da região sul do Brasil, como ocorre na bacia hidrográfica do Alto Iguaçu, e os resultados 
demonstraram que a bacia do Ribeira apresenta uma significativa redução pluviométrica, justamente ao que se atribui a redução das chuvas para os meses de outono e inverno, condição própria ao clima tropical do Brasil Central, conforme apontado por Nimer (1989), Nery et. al. (2002), Nery (2006), Silva et. al. (2006), Aparecido et. al. (2016) e Wrege et. al. (2016).
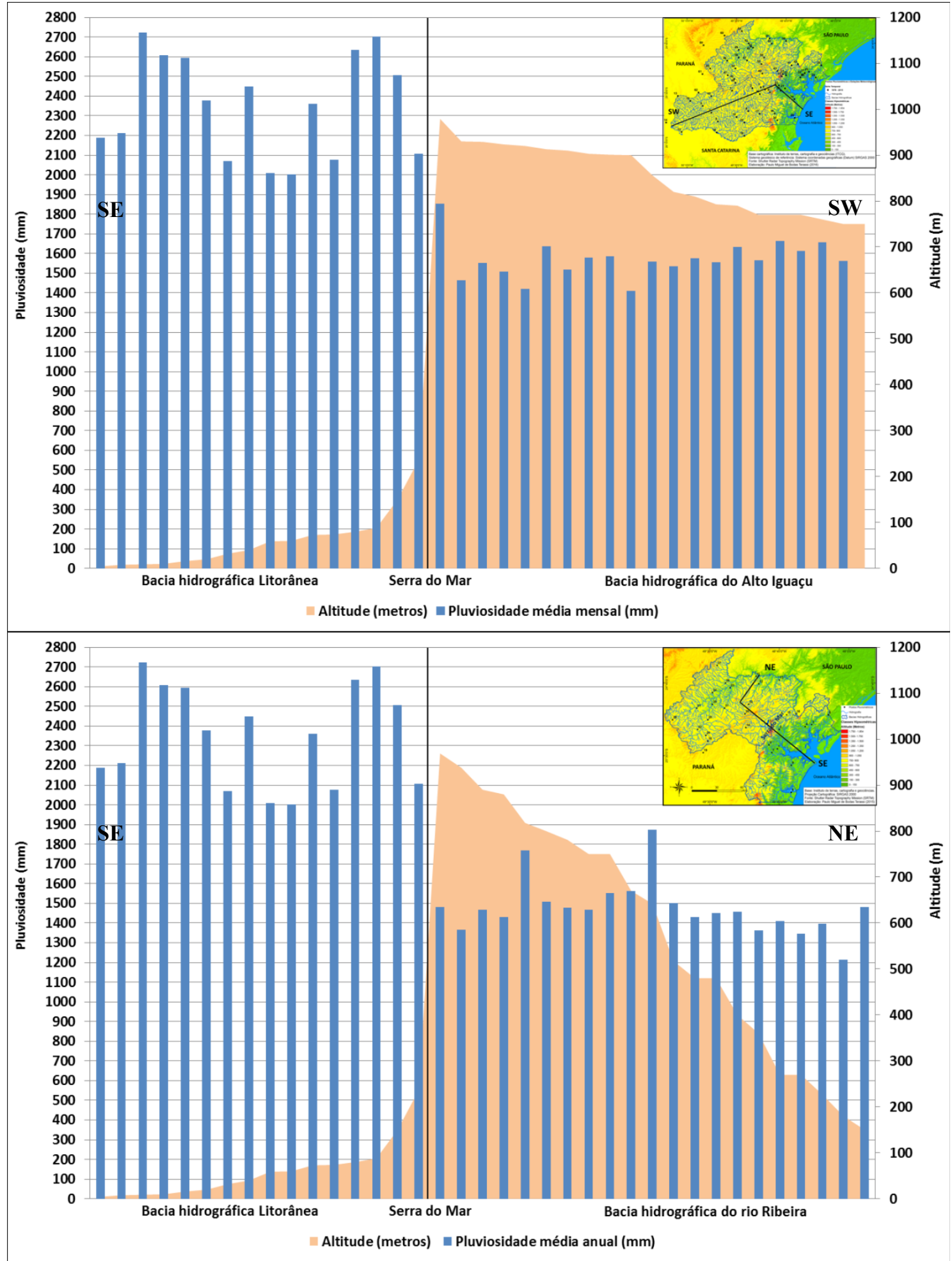

Figura 7 - Perfil esquemático da precipitação pluviométrica média anual (mm) e a altitude dos postos pluviométricos e estações meteorológicas das bacias hidrográficas Alto Iguaçu, Litorânea e Ribeira - Paraná. 
A área de estudo apresenta maiores totais mensais pluviométricos entre outubro e março (Figura 10), período que concentra cerca de $70 \%$ dos totais anuais (Figura 8) e, inversamente, o período de abril a agosto caracteriza-se pelos menores totais mensais pluviométricos (Figura 11). Os maiores totais pluviométricos ocorrem em janeiro, com média de $237 \mathrm{~mm}$, de valores superiores a $400 \mathrm{~mm}$ no setor litorâneo e inferiores a $200 \mathrm{~mm}$ para grande parte da bacia hidrográfica Alto Iguaçu. O mês menos chuvoso é agosto, com média de 78,9 mm, verificando-se a ocorrência de maiores isoietas na bacia hidrográfica Litorânea, superiores a $110 \mathrm{~mm}$, e menores valores para a região do Vale do Ribeira, inferiores a $60 \mathrm{~mm}$ (Figura 9).

Estes resultados são aproximados aos obtidos por Grimm (2009) e Fritzsons et. al. (2011), uma vez que estes observaram que a costa litorânea paranaense caracteriza-se pelos maiores totais pluviométricos anuais e com uma marcada concentração das chuvas nos meses de verão, sem estação seca, constantemente com precipitação média superior a $90 \mathrm{~mm}$ nos meses menos chuvosos. No setor continente adentro, estes autores observaram que no Centro-Sul do território paranaense, os totais pluviométricos anuais são menores em relação à costa litorânea e, no entanto, observa-se uma distribuição homogênea pluviométrica mensal, característica inerente ao clima subtropical do Sul do Brasil. A região do Vale do Ribeira, por sua vez, corresponde a um dos setores de menores alturas pluviométricas do estado do Paraná, com uma expressiva concentração das chuvas nos meses de verão, evidenciando uma tendência de aproximação com o clima tropical do Brasil Central (SILVA et. al., 2006; SILVA et. al., 2015).

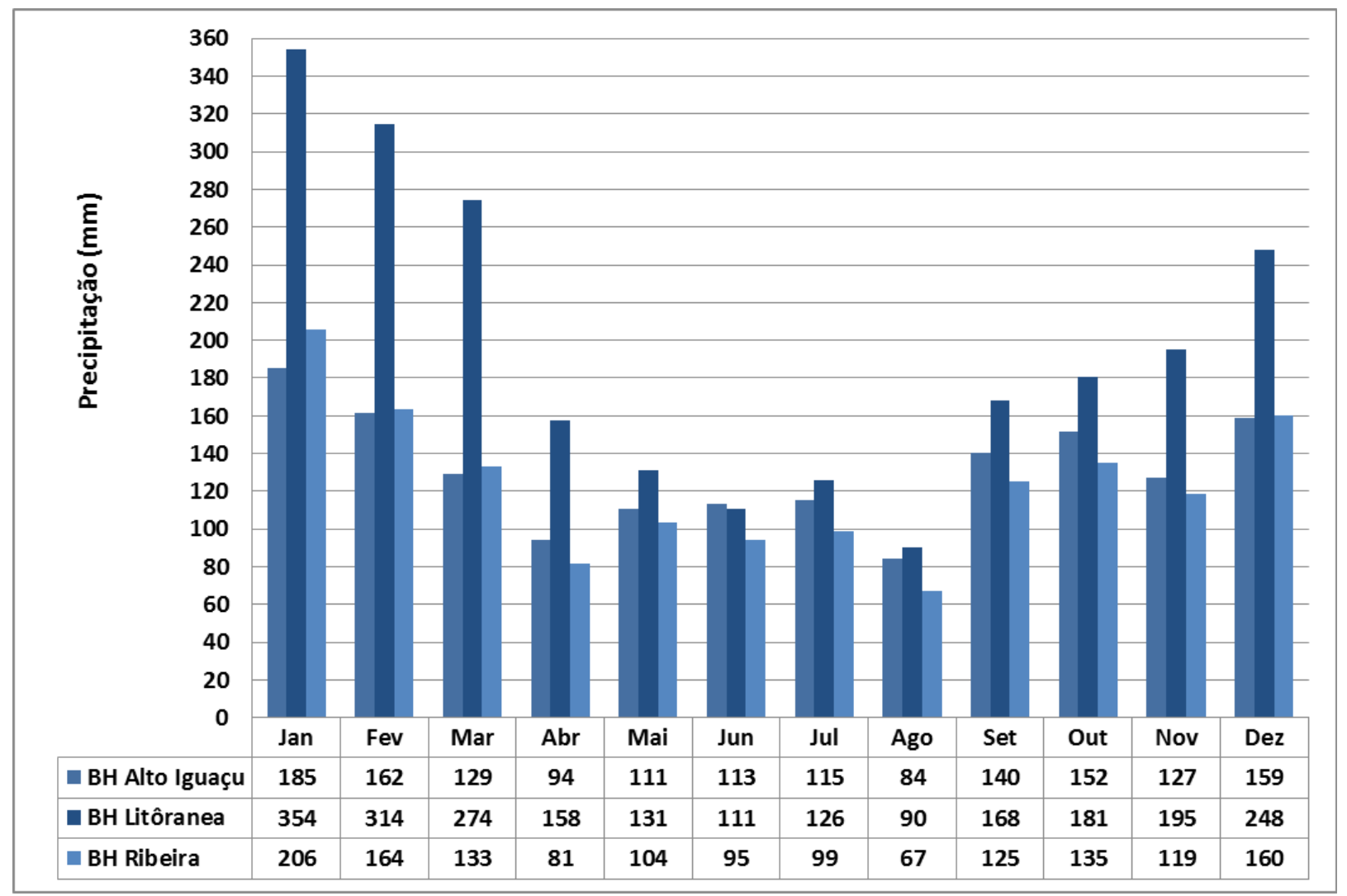

Figura 8 - Distribuição média mensal da precipitação pluviométrica (mm) das bacias hidrográficas Alto Iguaçu, Litorânea e Ribeira Paraná. 

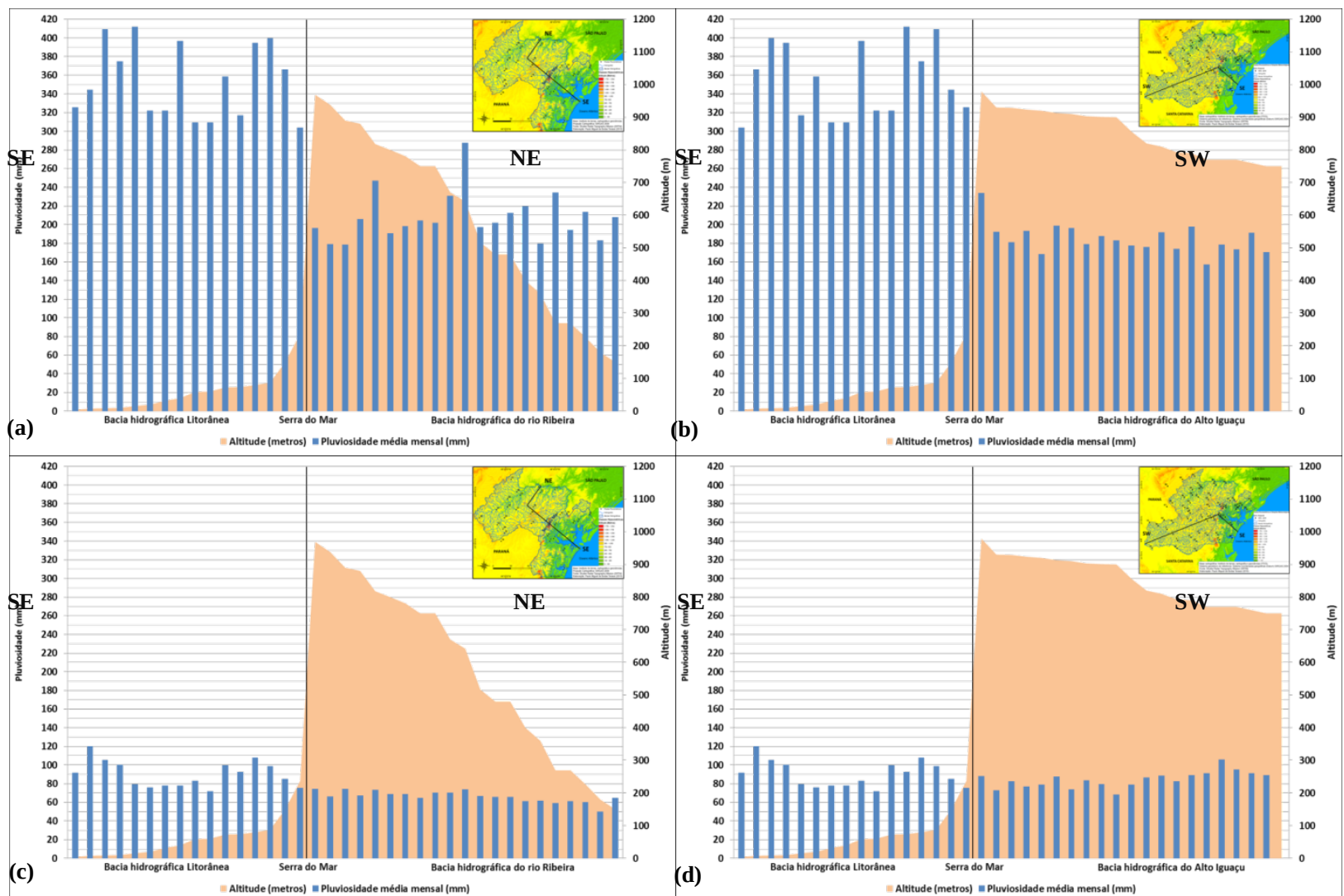

(b)

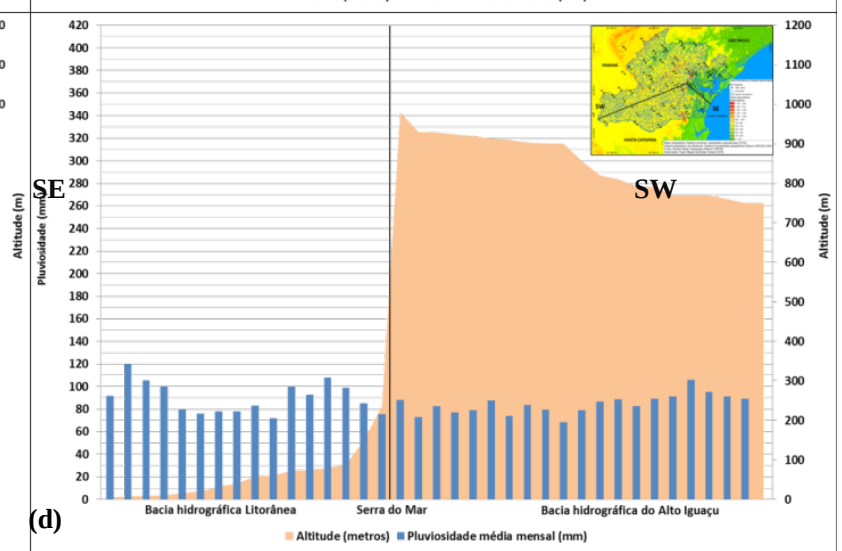

Figura 9 - Perfil esquemático da pluviosidade média mensal (mm) para os meses de janeiro em (a - b) e agosto (c - d) e a altitude dos postos pluviométricos e estações meteorológicas inseridas nas bacias hidrográficas do Alto Iguaçu, Litorânea e Ribeira - Paraná.

Em concordância ao obtido em outras bacias hidrográficas por Andrade e Nery (2003) e Candido e Nunes (2008), observa-se que os setores com maiores variações do relevo, sobretudo nas proximidades da Serra do Mar, mostraram as maiores variações dos totais pluviométricos. De modo inverso, os setores com as menores diferenças das altitudes mostraram as menores variações espaciais, especialmente na bacia hidrográfica do Alto Iguaçu. Nota-se que durante os meses de inverno, no período que vai de junho a agosto, a distribuição espacial das chuvas apresenta menores intervalos em relação ao período de verão, dado que os mecanismos de predominantes na geração de chuvas, os sistemas frontais, atuam de forma mais homogênea em relação ao verificado para os meses de verão e primavera (BORSATO; MENDONÇA, 2015,CARDOZO et. al., 2015; ZANDONADI et. al., 2015). 


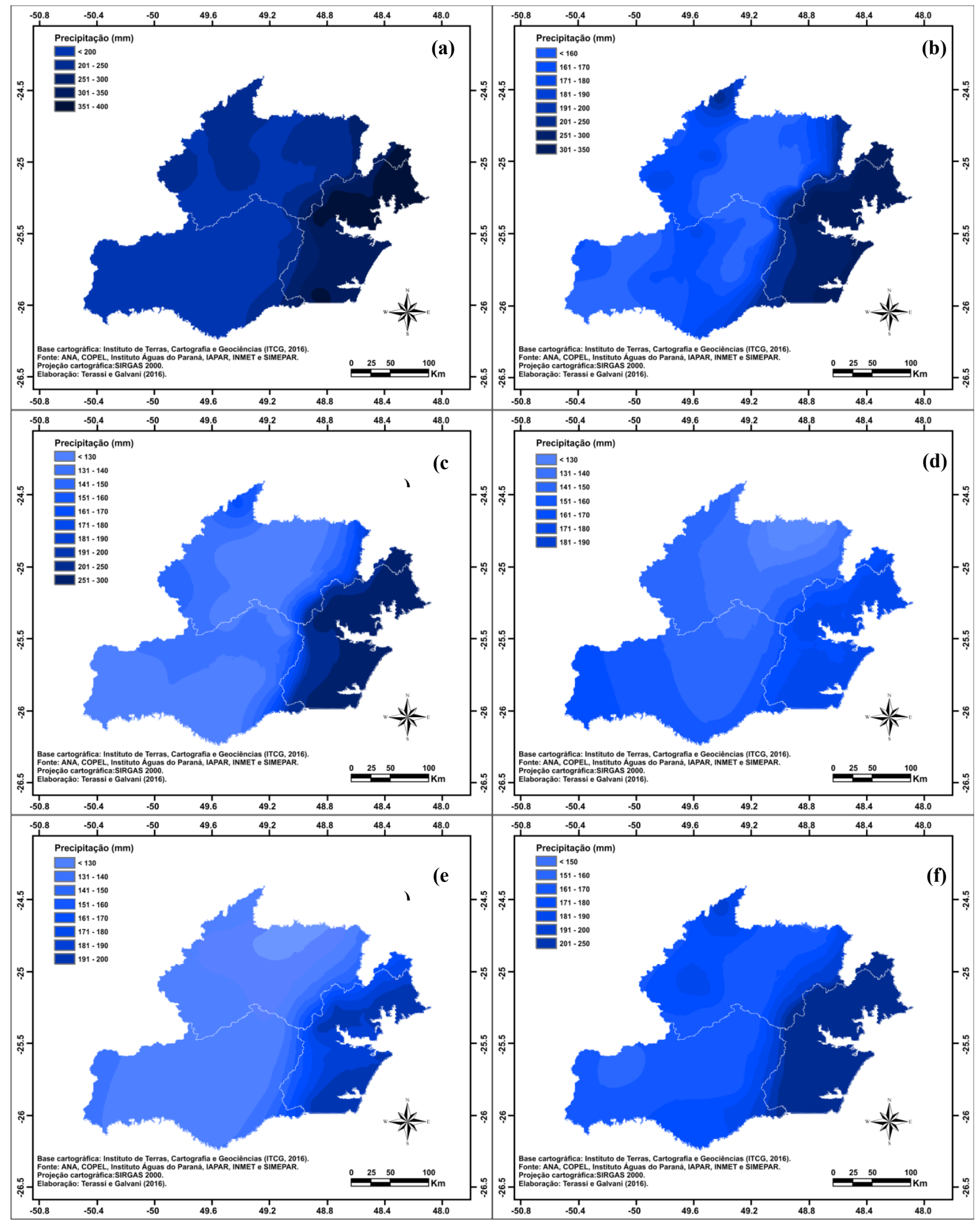

Figura 10- Distribuição espacial da pluviosidade média mensal (mm) para os meses de janeiro (a), fevereiro (b), março (c), outubro (d), novembro (e) e dezembro (f)para as bacias hidrográficas Alto Iguaçu, Ribeira e Litorânea - Paraná. 


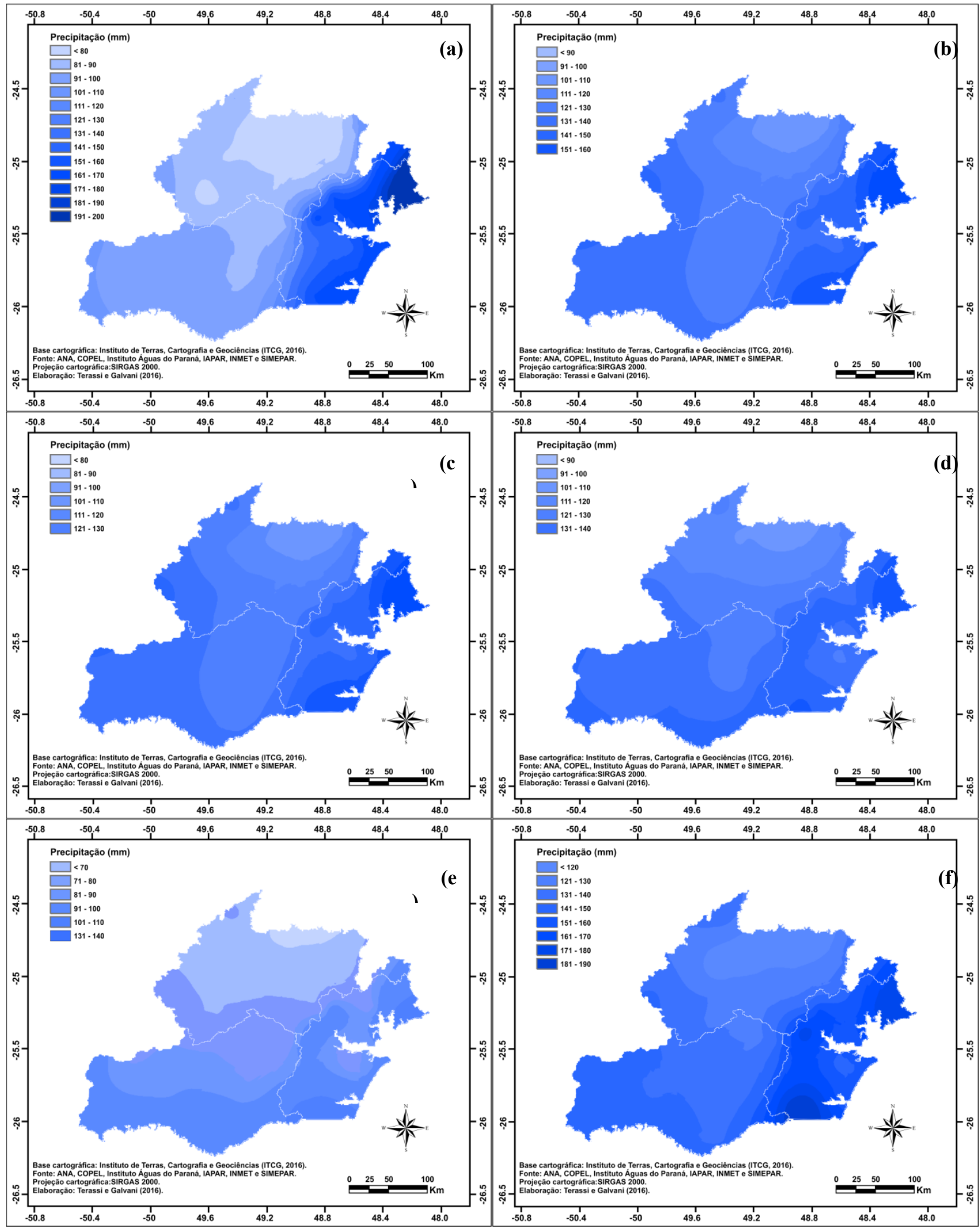

Figura 11- Distribuição espacial da pluviosidade média mensal (mm) para os meses de abril (A), maio (B), junho (C), julho (D), agosto (E) e setembro (F) para as bacias hidrográficas Alto Iguaçu, Ribeira e Litorânea - Paraná. 


\section{Conclusões}

Os resultados demonstraram que a bacia hidrográfica Litorânea caracteriza-se pela maior precipitação pluviométrica média, com registros de postos pluviométricos em que as médias anuais foram próximas a $2.700 \mathrm{~mm}$, demonstrando o papel desempenhado pela maritimidade para o acréscimo dos totais de pluviosidade neste setor da área em estudo. Com a barreira orográfica da Serra do Mar, a bacia hidrográfica do rio Ribeira obteve os menores valores da precipitação pluvial média anual, com postos nos quais a média anual esteve próxima a $1.200 \mathrm{~mm}$. Dado o desempenho orográfico da Serra do Mar, a bacia hidrográfica do Alto Iguaçu apresenta igualmente menores médias anuais de chuva em relação à bacia hidrográfica Litorânea e, devido a pouca variação da hipsometria, observou-se uma relativa homogeneidade da distribuição espacial da precipitação pluvial nesta bacia hidrográfica.

A área em estudo caracteriza-se pela concentração dos maiores totais de pluviosidade no período de primavera e verão, que vai de setembro a março, e a redução no outono e inverno, de abril a agosto. Os meses de inverno mostraram as menores diferenças de pluviosidade entre as bacias hidrográficas, o que se atribui a atuação homogênea dos sistemas frontais, principal mecanismo de geração das chuvas durante este período. Observou-se que a bacia hidrográfica Litorânea apresenta os maiores totais médios de precipitação pluvial em todos os meses do ano, com maiores aumentos de pluviosidade nos meses de verão dada a sua condição de proximidade ao Oceano Atlântico. Devido à sua proximidade com o domínio climático subtropical, notou-se que a bacia hidrográfica do Alto Iguaçu apresenta a maior regularidade mensal das precipitações, enquanto que a bacia hidrográfica do Ribeira demonstrou de forma mais notável similaridades com o clima tropical do Brasil Central dada a concentração pluvial nos meses de primavera e verão e a redução durante o inverno.

\section{Agradecimentos}

O presente trabalho foi realizado com apoio do Programa Nacional de Cooperação Acadêmica da Coordenação de Aperfeiçoamento de Pessoal de Nível Superior - CAPES/Brasil - Edital CAPES 071/2013 - Processo número 88881.068465/2014-01. Os autores também agradecem à Coordenação de Aperfeiçoamento de Pessoal de Nível Superior (CAPES) e ao Conselho Nacional de Desenvolvimento Científico e Tecnológico (CNPq) pela concessão das bolsas de estudos de Doutorado aos dois primeiros autores e à Bolsa de Produtividade em Pesquisa do CNPq - Nível 1Dpara o terceiro autor (303676/2013-2).

\section{Referências}

ÁLVARES CA, STAPE JL, SENTELHAS PC, DE MORAES GONÇALVES JL, SPAROVEK G. Köppen's climate classification map for Brazil. Meteorologische Zeitschrift.2013, 22 (6), 711-728.

ANDRADE AR, NERY JT. Análise da precipitação pluviométrica diária, mensal e interanual da bacia hidrográfica do Rio Ivaí, Brasil. Investigaciones Geográficas. 2003, 52 (1), 7-30.

APARECIDO LEO, ROLIM GS, RICHETTI J, SOUZA OS, JOHANN JA. Köppen, Thornthwaite and Camargo climate classifications for climatic zoning in the State of Paraná, Brazil.Ciência e Agrotecnologia (Online). 2016, 40 (4), 405-417.

ARAÚJO LE, SOUSA FAS, RIBEIRO MAFM, SANTOS AS, MEDEIROSPC. Análise estatística de chuvas intensas na bacia hidrográfica do rio Paraíba. Revista Brasileira de Meteorologia. 2008, 23 (2), $162-169$. 
BORSATO VA,MENDONÇA FA. Participação da massa polar atlântica na dinâmica dos sistemas atmosféricos no Centro Sul do Brasil. Mercator. 2015, 14 (1), 113-130.

CÂNDIDO DH, NUNES LH. Influência da orografia na precipitação da área entre o vale do rio Tietê e a Serra da Mantiqueira. Geousp. 2008, 24 (1), 8-27.

CARDOZO AB, REBOITA MS, GARCIA SR. Climatologia de Frentes Frias na América do Sul e sua relação com o Modo Anular Sul. Revista Brasileira de Climatologia. 2015, 17 (1), 9-29.

CARVALHO JRP, ASSAD ED. Análise espacial da precipitação pluviométrica no estado de São Paulo: comparação de métodos de interpolação. Engenharia Agrícola. 2005,25 (2), 377-384.

CARVALHO RG. As bacias hidrográficas enquanto unidades de planejamento e zoneamento ambiental no Brasil. Caderno Prudentino de Geografia. 2014. v. especial (36), 26-43.

CAVAGLIONE JH, KIIHL LRB, CARAMORI PH, OLIVEIRA D. Cartas climáticas do Paraná. Londrina: IAPAR; 2000.

CHIERICE RAF, LANDIM PMB. Variabilidade espacial e temporal de precipitação pluviométrica na bacia hidrográfica do rio Mogi Guaçu. Geociências. 2014,33 (1), 157-171.

FORGIARINI FR, VENDRUSCULO DS, RIZZI ES. Análise de chuvas orográficas no centro do estado do Rio Grande do Sul. Ciência \& Natura. 2014, 36 (2), 193-200.

FRITZSONS E, MANTOVANI LE, WREGE MS, CHAVES NETO A. Análise da pluviometria para definição de zonas homogêneas no estado do Paraná. RA'E GA: o Espaço Geográfico em Análise. 2011, 23(1), 555572 .

GOIS G, DELGADO RC, OLIVEIRA-JÚNIOR JF. Modelos teóricos transitivos aplicados na interpolação espacial do standardized precipitation index (SPI) para os episódios de El Niño forte no estado do Tocantins, Brasil. Irriga. 2015, 20 (2), 371-387.

GRIMM AM. Clima na Região Sul. In: CAVALCANTI IFA, FERREIRA NJ, JUSTI DA SILVA MGA, SILVA DIAS MAF (Editores). Tempo e Clima no Brasil. 1aㅡ Edição. São Paulo, Oficina de Textos; 2009. p.259-275.

ITCG (Instituto de Terras, Cartografia e Geodésia). Produtos Cartográficos. Disponível em: <http://www. itcg.pr.gov.br/modules/conteudo/conteudo.php? conteudo=47. Acesso em 28 de agosto de 2016.

KÖPPEN W. Climatologia: com un estúdio de los climas de latierra. México: Ed. Fondo de Cultura Econômica; 1948. 479p.

LANDIM PMB. Análise estatística de dados geológicos. $2^{\text {a }}$ Edição. São Paulo, Editora da UNESP; 2004. 256 .

LEIVAS JF,BERLATO MA, FONTANA DC. Risco de deficiência hídrica decendial na metade sul do Rio Grande do Sul. Revista Brasileira de Engenharia Agrícola e Ambiental. 2006, 10 (2), $397-407$.

LEOPOLD LB. The interaction of trade wind and e sea breeze. Journal of Meteorology.1949, 6 (5), 312-320.

MAACK R. Geografia Física do Estado do Paraná. 4ª Edição. Ponta Grossa: Editora UEPG; 2012.

MELLO YR, OLIVEIRA TMN. Análise estatística e geoestatística da precipitação média para o município de Joinville (SC). Revista Brasileira de Meteorologia. 2016,31 (2), 229-239.

MILANESI MA, GALVANI E. Efeito orográfico na Ilha de São Sebastião (Ilha Bela - SP). Revista Brasileira de Climatologia. 2011, 9 (2), 68-79. 
MINEROPAR. Atlas Geológico do Estado do Paraná. Curitiba: Minerais do Paraná; 2001.

NERY JT, MARTINS MLF, SANTANNA NETO JL. Variabilidade da precipitação no Brasil Meridional. Acta Scientiarum Technology (UEM). 2002, 24 (6), 1687-1695.

NERY JT. Dinâmica climática da região Sul do Brasil. Revista Brasileira de Climatologia. 2006, 1 (1), 6175.

NIMER E. Climatologia do Brasil. 2ª Edição. Rio de Janeiro: Instituto Brasileiro de Geografia e Estatística; 1989.

OLIVEIRA LFC, FIOREZE AP, MEDEIROS AMM, SILVA MAS. Comparação de metodologias de preenchimento de falhas em séries históricas de precipitação pluvial anual. Revista Brasileira de Engenharia Agrícola e Ambiental. 2010, 14 (11), 1186-1192.

PELL MC, FINLAYSON BL, MCMAHON TA. Update world map of the Köppen - Geiger climate classification. Hydrology and Earth System Sciences. 2007, 11 (1), 1633-1644.

PEREIRA AR, ANGELOCCI LR, SENTELHAS PC. Agrometeorologia: fundamentos e aplicações práticas. Guaíba: Editora Agropecuária; 2002.487p.

PORTO MFA, PORTO RLL. Gestão de bacias hidrográficas. Estudos Avançados. 2008, 22 (63), 43-60.

SANT'ANNA NETO JL. Dinâmica atmosférica e o caráter transicional do clima na Zona Costeira Paulista. Revista do Departamento de Geografia (USP). 1994, 8 (1), 35-49.

SELUCHI ME, CHAN CHOU S, GRAMANI M. A case study of a winter heavy rainfall event over the Serra do Mar in Brazil. Geofísica Internacional. 2011, 50 (1), 41-56.

SILVA CB, SANT'ANNA NETO JL, TOMMASELLI JTG, PASSOS MM. Dinâmica atmosférica e análise geoestatística do clima na área de integração paisagística 'Raia Divisória' SP/PR/MS: uma proposta de tipologia climática. Revista Brasileira de Climatologia. 2006, 2 (1), 53-70.

SILVA WL, DERECZYNSKI C, CHANG M, FREITAS M, MACHADO BJ, TRISTÃO L, RUGGERI J. Tendências observadas em indicadores de extremos climáticos de temperatura e precipitação no Estado do Paraná. Revista Brasileira de Meteorologia. 2015, 30 (2), 181-194.

THOMAZ SL. Sinopse sobre a geologia do Paraná. Boletim de Geografia. 1984, 2 (2), 76-90.

VANHONI F, MENDONCA FA. O clima no litoral do Estado do Paraná. Revista Brasileira de Climatologia. 2008, 3 (1), 49-64.

VILLELA SM, MATTOS A. Hidrologia aplicada. São Paulo: McGraw-Hill do Brasil; 1975. 245p.

WREGE MS, FRITZSONS E, CARAMORI PH, RICCE WS, RADIN B, STEINMETZ S. REISSER JÚNIOR C. Regiões com similaridade de comportamento hídrico no Sul do Brasil. RA’E GA: o Espaço Geográfico em Análise. 2016, 38 (1), 363-382.

YAKAMOTO JK, LANDIM PMB. Geoestatística: Conceitos e Aplicações. $1^{\underline{a}}$ Edição. São Paulo: Oficina de Textos; 2013.

ZANDONADI L, ACQUAOTTA F, FRATIANNI S, ZAVATTINI JA. Changes in precipitation extremes in Brazil (Paraná River Basin).Theoretical and Applied Climatology. 2015, 119 (1), 741-756. 